\title{
Quality of Diabetes Care in Primary Health Centres in North Al-Batinah of Oman
}

\author{
Mohammed Al-Shafaee ${ }^{*}, 1$, Yousuf Al-Farsi ${ }^{1}$, Yousuf Al-Kaabi ${ }^{1}$, Yajnavalka Banerjee ${ }^{2,3}$, \\ Najat Al-Zadjali ${ }^{1}$ and Ibrahim Al-Zakwani ${ }^{4,5}$
}

\author{
${ }^{I}$ Department of Family Medicine and Public Health, College of Medicine and Health Sciences, Sultan Qaboos \\ University, Muscat, Oman \\ ${ }^{2}$ Department of Biochemistry, College of Medicine and Health Sciences, Sultan Qaboos University, Muscat, Oman \\ ${ }^{3}$ Familial Hypercholesterolemia Study Group, Oman Society for Lipid and Atherosclerosis (OSLA), Muscat, Oman \\ ${ }^{4}$ Department of Pharmacology \& Clinical Pharmacy, College of Medicine and Health Sciences, Sultan Qaboos \\ University, Muscat, Oman \\ ${ }^{5}$ Gulf Health Research, Muscat, Oman
}

\begin{abstract}
Objective: To assess the quality of diabetic care provided in primary health care settings in Oman.
Methods: This was a cross-sectional study of randomly selected 500 patients with diabetes mellitus (DM) attending 6 primary care diabetic clinics in the north Al-Batinah region of Oman from January to December 2010. Nine standards on the quality of diabetes care were audited.

Results: The mean age of the sample was $51 \pm 13$ years, ranging from 15 to 87 years; the majority (61\%) were females. The mean duration of DM was $4 \pm 3$ years, ranging from 1 to 18 years. Seventy-seven percent of the patients attended diabetic clinics at least 4 times per year. Of the 9 assessed diabetic standards, HbA1c was documented in 33\% of the patients, body mass index in $12 \%$, low-density lipoprotein cholesterol (LDL-C) in $40 \%$, urinary albumin:creatinine ratio in $28 \%$, creatinine in $63 \%$ and blood pressure (BP) in $96 \%$. Optimal control among the documented indicators was noted in 32, 21 , $25,85,95$ and $19 \%$, respectively. Twenty percent of the patients had their ECGs done while only $39 \%$ of the patients had foot examination. No patient had attained control in all of HbA1c., BP and LDL-C.

Conclusion: There is a gap between the recommended DM care guidelines and current practice with consequent poor quality of care in these patients.
\end{abstract}

Keywords: Arab, diabetes mellitus, diabetic standards, Oman, quality of care.

\section{INTRODUCTION}

Diabetes mellitus (DM) is considered as a major public health problem in Oman and the World at large [1-6]. The disease is the foremost cause of blindness, end-stage renal failure, non-traumatic limb amputations, and cardiovascular morbidity and mortality [7]. Several future projections of the prevalence, incidence, and total number of DM cases for the US and other countries have been carried out. Projections for the year 2025 show that the prevalence of DM is increasing and the global burden of DM is estimated to increase by $122 \%$, with a total of 308 million people being affected [1, 2, 7] but since 2000, the number of people with DM has more than doubled to 285 million [3]. In a recent study,

*Address correspondence to this author at the Department of Family Medicine and Public Health, College of Medicine \& Health Sciences, Sultan Qaboos University, P.O. Box: 35, Postal Code 123, Al-khod, Sultanate of Oman; Tel: +968-2414-1128; Fax: +968-24413419

E-mail: shafaee@squ.edu.om it was shown that the annual diagnosed DM incidence (new cases) will increase from about 8 cases per 1,000 in 2008 to about 15 per 1,000 in 2050 . If it is assumed that there is a low incidence and relatively high DM mortality, cumulative DM prevalence (diagnosed and undiagnosed cases) is anticipated to increase from $14 \%$ in 2010 to $21 \%$ of the US adult population by 2050 . Further, if current increases in DM incidence continue and DM mortality is relatively low, prevalence will increase to $33 \%$ by 2050 . A middle-ground picture projects an incidence of 25 to $28 \%$ by 2050 . The most disquieting fact of this study was that intervention can reduce, but not eliminate, increases in DM prevalence [5].

In the Eastern Mediterranean Region, DM is expected to increase by $150 \%$ in the first quarter of this century [8]. This problem is also reflected in the Middle East where the prevalence of type $2 \mathrm{DM}$ in 2007 varied between $3.4 \%$ in the Yemen to $19.5 \%$ in the UAE in patients between 20-79 years of age [9]. In Oman, the prevalence of type 2 DM in 2009 
was $12 \%$ as mentioned by the annual health report indicating steady increase in its prevalence [10]. The World Health Organization (WHO) estimates a 190\% increase in the number of people living with DM in Oman over the coming years, from 75,000 in 2000 to 217,000 in 2025 [11]. All these figures support the fact that type $2 \mathrm{DM}$ is a major public health problem in Oman.

DM imposes a huge economic burden on national health care systems and impinges on both national economies, individuals and their families. Direct medical costs consist of resources used to manage the disease. Indirect costs include lost productivity caused by morbidity, disability and premature mortality. Further, costs refer to the reduced quality of life for people with DM [12]. Therefore, there is an urgent need to continuously assess and improve the care of patients with type $2 \mathrm{DM}$. Further studies have shown that good control of blood pressure and glucose lead to significant reductions of cardiovascular complications among patients with type 2 DM [13-15], which indicates that effective patient care can significantly reduce the detrimental consequences associated with this disease.

The management of patients with type $2 \mathrm{DM}$ is complex. Good control significantly reduces the risk of complications. However, studies from around the world consistently report inappropriate disparity in care [16-18]. Preceding research conducted with regards to DM care has categorized several relevant factors under the wide-ranging headings of patient, health professional and organizational factors [19]. Ideally, quality upgrading efforts should be underpinned by more specific knowledge of modifiable factors. Additionally, factors identified in prior work from Europe and North America may not be assignable to other cultures. Case in point, the population of Oman is relatively genetically homogenous [20], in comparison with other populations. Therefore, patient care associated with type 2 DM in Oman may have unique and specific requirements, compared with those practiced in other populations. This necessitates that a continuous assessment of patient care associated with type 2 DM is carried out, in order to identify the precise need, facilitating patient care.

However, at present only one study in the literature assessed the quality of primary care provided for patients with DM in Oman. This study was conducted in the capital city of Muscat. It showed that $2.4 \%$ of patients were within target for $\mathrm{HbAlc}$ and other standards according to the Ministry of Health $(\mathrm{MoH})$ for guideline [6]. However, information with regards to the quality of care for patients with type $2 \mathrm{DM}$ in the other regions of the country is currently lacking. The purpose of this study therefore is to assess the quality of diabetic care provided in primary care setting in North Al-Batinah governorate of Oman, one of the largest governorates in the country, with a total of 16,000 patients with DM [4].

\section{METHODS}

This study was conducted in the north Al-Batinah governorate between January and December 2010. This region consists of 6 districts (known as wilayaat) and about 23 health centers ranging from 2 to 4 heath centers for each district. The total number of patients with DM in this governorate is about 16,000 as of the end of December 2010 according to the $\mathrm{MoH}$ annual report [22]. Health centers with less than 100 patients with DM were excluded. One health center was then selected randomly from each district. The target population in the 6 selected heath centers was 8,365 patients with DM. Sample size was generated using data from the literature and the statistical program, "epi-info" (Centers for Disease Control and Prevention (CDC), Atlanta, GA, USA). This resulted in a required sample size of 500 patients with $95 \%$ confidence level and $\pm 3 \%$ accuracy. The number of patients from each health center was selected proportionally according to a stratified sampling method followed by simple random sampling from each of the selected centers. See Table $\mathbf{1}$ for details.

Exclusion criteria included patients who did not attend diabetic clinics in the preceding year. Depending on the $\mathrm{MoH}$ guidelines for the management of DM in primary health care, a checklist included patient demographic data; process of care which included whether the measurements had been recorded in the last 12 months, and outcome of care which included the result of those measurements. Nine standards of care were measured that included $\mathrm{HbA}_{1 \mathrm{c}}(<7 \%)$, body mass index (BMI) (18.5-24.9), low-density lipoprotein cholesterol (LDL-C) $(<2.6 \mathrm{mmol} / \mathrm{L})$, urinary albumin: creatinine ratio (ACR) ( $<3.5$ for females, $<2.5$ for males), serum creatinine level $(<120 \mu \mathrm{mol} / \mathrm{L})$, blood pressure (BP) $(<130 / 80 \mathrm{mmHg}$ ), electrocardiogram (ECG) (once/year),

Table 1. Contribution of each health center's sample size.

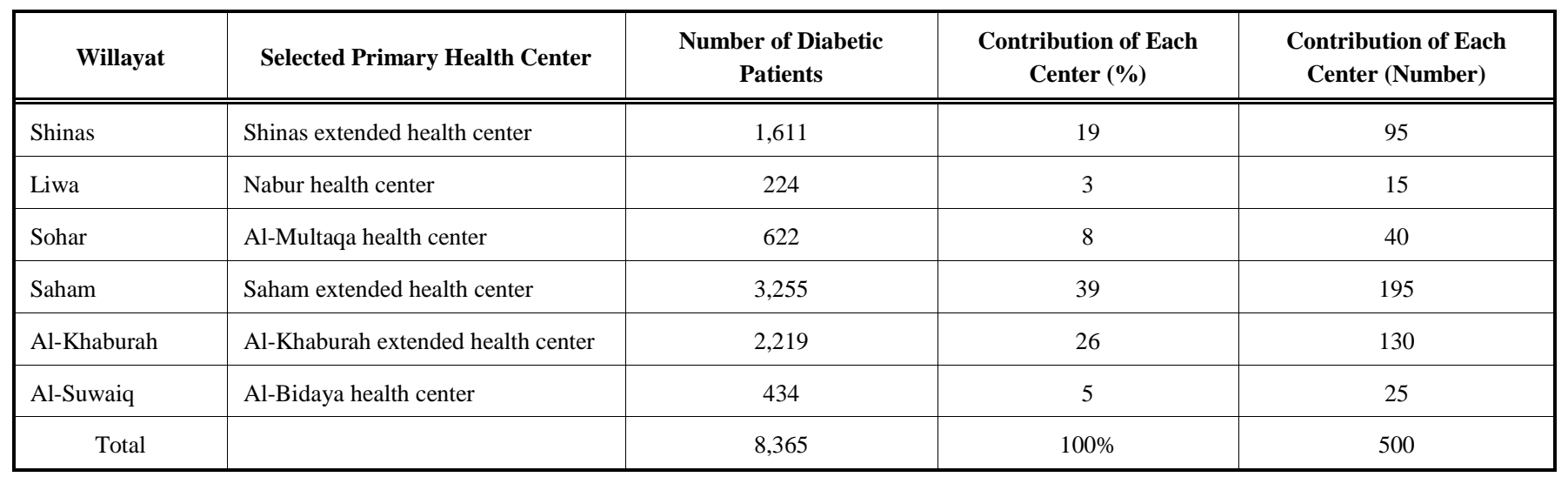


foot examination (each visit) and annual retinal checkup (once/year). The checklist also included antihypertensive, glucose and lipid lowering medications. Data was collected by the investigators from manual and electronic records after obtaining ethical approval from the Research and Ethics Committee in the College of Medicine and Health Sciences at Sultan Qaboos University (MREC\#492) and from North Al-Batinah governorate.

\section{Statistical Analysis}

Descriptive statistics were used to summarize the data. For categorical variables, frequencies and percentages were reported. Differences between groups were analyzed using Pearson's $\chi^{2}$ tests (or Fisher's exact tests for cells <5). For continuous variables, means and standard deviations (SD) were presented and analyses were conducted using Student's t-tests. An a priori two-tailed level of significance was set at 0.05. Statistical analyses were performed using STATA version 12.1 (College Station, Texas, USA).

\section{RESULTS}

The overall mean age of the sample was $51 \pm 13$ years, ranging from 15 to 87 years; the majority (61\%) were females. The mean duration of DM in the sample was $4 \pm 3$ years, ranging from 1 to 18 years. The majority of the patients $(77 \%)$ attended a diabetic clinic at least 4 times/year; only $16 \%$ of them had type 1 DM.

The first set of analyses examined the measurement of BMI and showed that BMI was not measured in $88 \%$ of the sample. The mean BMI among the 58 patients who had their BMI measured was $29 \pm 6$, ranging from 15 to 39 . On other hand, $96 \%$ of the patients who were included in the study, had their BP measured at least twice/year. However, only $19 \%$ of the patients with DM had controlled BP with readings $<130 / 80 \mathrm{mmHg}$. Diastolic $\mathrm{BP}$ was $<80 \mathrm{mmHg}$ in 121 patients and systolic BP was $<130 \mathrm{mmHg}$ in 209 patients. More than two thirds of the selected patients had no $\mathrm{HbA}_{1 \mathrm{c}}$ result as shown in Fig. (1).
Among the reported $\mathrm{HbA}_{1 \mathrm{c}}$ levels (165 patients), the mean was $8.4 \pm 2.2 \%$, ranging from 5 to $14 \%$ and only one third (53 patients) had met the target of $<7 \%$. There was no statistically significant difference in $\mathrm{HbA}_{1 \mathrm{c}}$ among patients from different clinics ( $\mathrm{p}>0.05)$.

About $40 \%$ of the patients had their LDL-C levels ordered and results are shown in Fig. (2). Among the reported LDL-C levels, only one fourth (51 patients) of the patients had met the goal of $<2.6 \mathrm{mmol} / \mathrm{L}$. There were statistically significant differences in LDL-C among patients from different clinics $(\mathrm{p}<0.001)$. Three quarters of the ordered and reported sample had high LDL-C $(\geq 2.6 \mathrm{mmol} / \mathrm{L})$ and only $58 \%$ of these patients were on a statin.

Out of the 500 patients, creatinine was measured in 314 patients (Fig. 3). As can be seen from Fig. (4), ACR results were available for only $28 \%$ of the patients and those patients were from only 2 out of the 6 health centers included in the study. It is apparent from Table 2 that only about $20 \%$ of the patients had ECGs. Only $39 \%$ of the patients had foot examination, while 2 health centers did not document any foot examinations at all. On the other hand, in 1 health center, $98 \%$ of patients had documented foot examination. It is also noticeable that only about half of the patients had an ophthalmology review.

Medications were not changed despite $\mathrm{HbA}_{1 \mathrm{c}}$ and $\mathrm{BP}$ values above the goals recommended for patients with DM. None of the patients in the study were on long acting insulin. A total of $24 \%(n=118)$ of patients had all values of $\mathrm{HbA}_{1 \mathrm{c}}$, BP and LDL-C. Overall, none $(0 \%)$ of the patients with DM had control in the 3 mentioned standards $\left(<7 \% \mathrm{HbA}_{1 \mathrm{c}}\right.$, $<130 / 80 \mathrm{mmHg}$ and $<2.6 \mathrm{mmol} / \mathrm{L} \mathrm{LDL-C}$ ).

\section{DISCUSSION}

This study offers insight into the quality of DM care in primary health care settings in the north Al-Batinah governorate of Oman. Information on DM care indicators has not been previously available on an extensive scale in Oman. The results of this study show that nearly $24 \%$ had

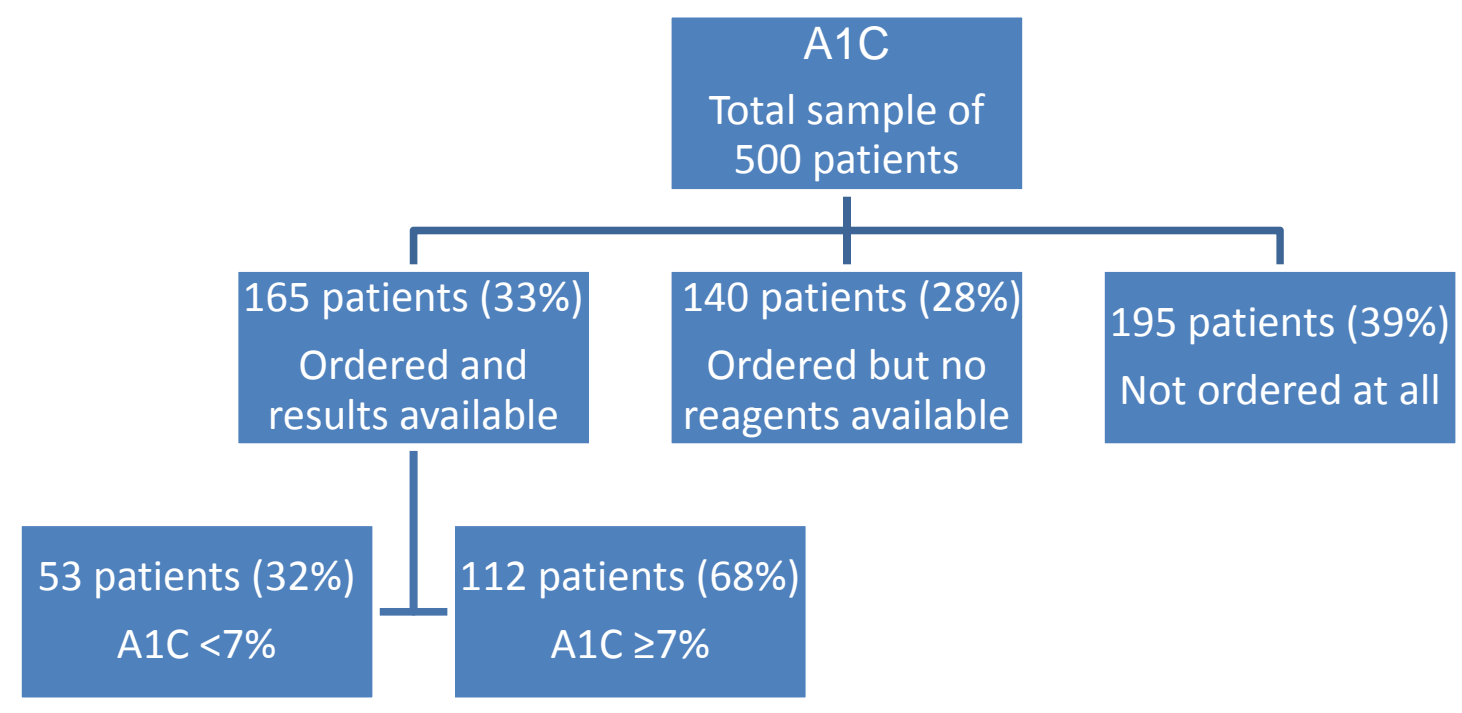

Fig. (1). Glycated hemoglobin (A1C) results. 
their BP, LDL-C and $\mathrm{HbA}_{1 \mathrm{c}}$ levels measured during the study. Disappointingly, the proportion of the patients meeting the controlled levels of these 3 parameters is zero.

A previous study showed that the control was extremely low $(2.4 \%)$ for meeting internationally recognized goals for the 3 DM-related outcomes [21]. Furthermore, our results are also consistent with the systematic review of the management of type $2 \mathrm{DM}$ in the Gulf Cooperation Council (GCC) region (based on glycaemic-, BP- and lipid- control indicators) which concluded that management of DM care is suboptimal in the Middle East [22]. Our results are also consistent with those of others at an international level which found that the initial control was $<10 \%$ in these 3 parameters $[23,24]$. Our results and those of other studies, hint towards the fact that optimal DM care should be based on more aggressive targets as patients with DM are at an increased risk for cardiovascular disease.

In the SANDS randomized trial, development of subclinical atherosclerosis in adults with type $2 \mathrm{DM}$ treated to reach aggressive targets LDL-C of $\leq 1.8 \mathrm{mmol} / \mathrm{L}$ and systolic
BP $\leq 115 \mathrm{mmHg}$ vs standard targets of LDL-C of $\leq 2.6$ $\mathrm{mmol} / \mathrm{L}$ and systolic $\mathrm{BP}$ of $\leq 130 \mathrm{mmHg}$ was assessed by measuring carotid artery intimal medial thickness (cIMT) as the primary end point. Reducing LDL-C and systolic BP to lesser targets lead to regression of cIMT and greater reduction in left ventricular mass in patients with type $2 \mathrm{DM}$ [25].

Additionally, with the advent of better therapeutic strategies, achievement of aggressive targets is feasible. For example, the new monoclonal antibody to proprotein convertase subtilisin/kexin type 9 serine protease (PCSK9), REGN727 was well tolerated and accomplished considerable further LDL-C reduction in patients with heterozygous familial hypercholesterolemia and elevated LDL-C treated with high-dose statins, with or without ezetimibe [26, 27]. Although phase III studies related to this and similar antibodies are still eagerly awaited, it would be interesting to assess the efficacy of these antibodies for more aggressive lowering of lipids especially in patients with DM.

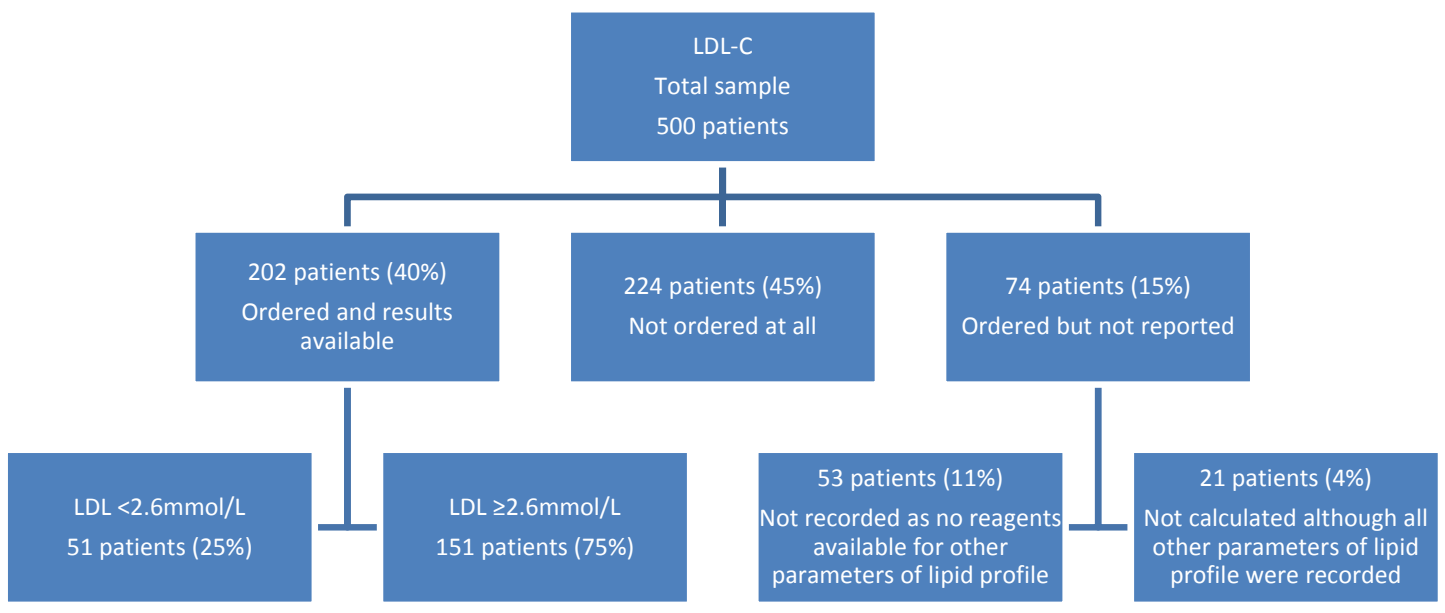

Fig. (2). Low-density lipoprotein cholesterol (LDL-c) results.

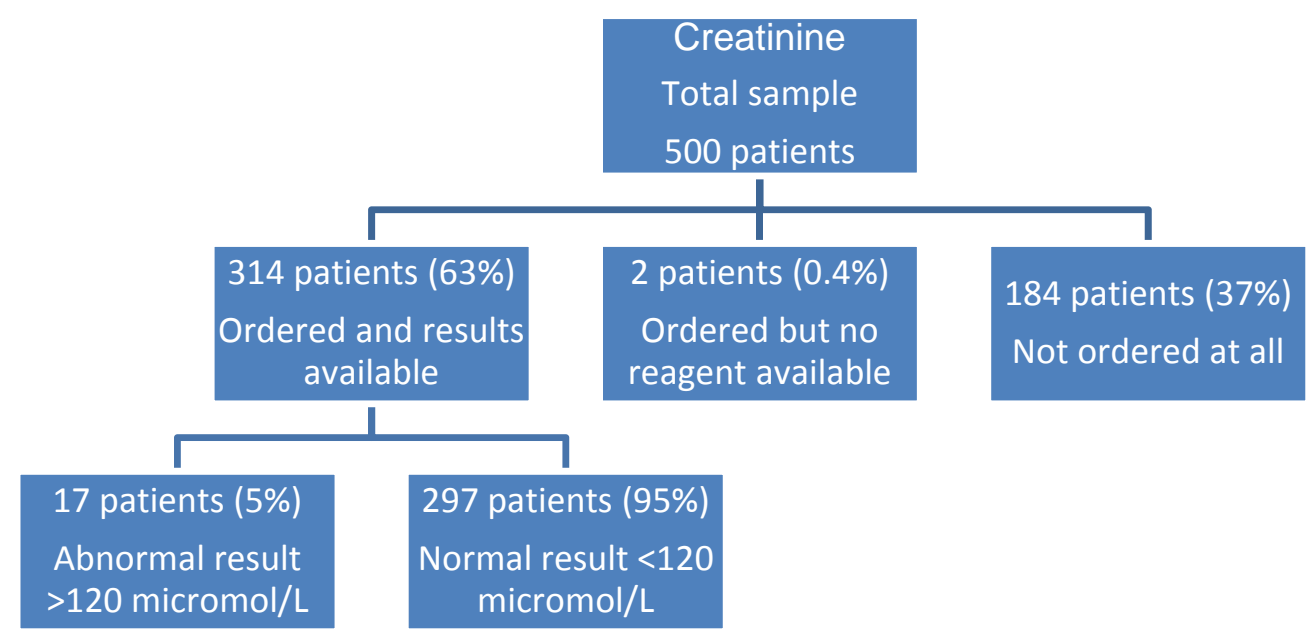

Fig. (3). Creatinine results. 


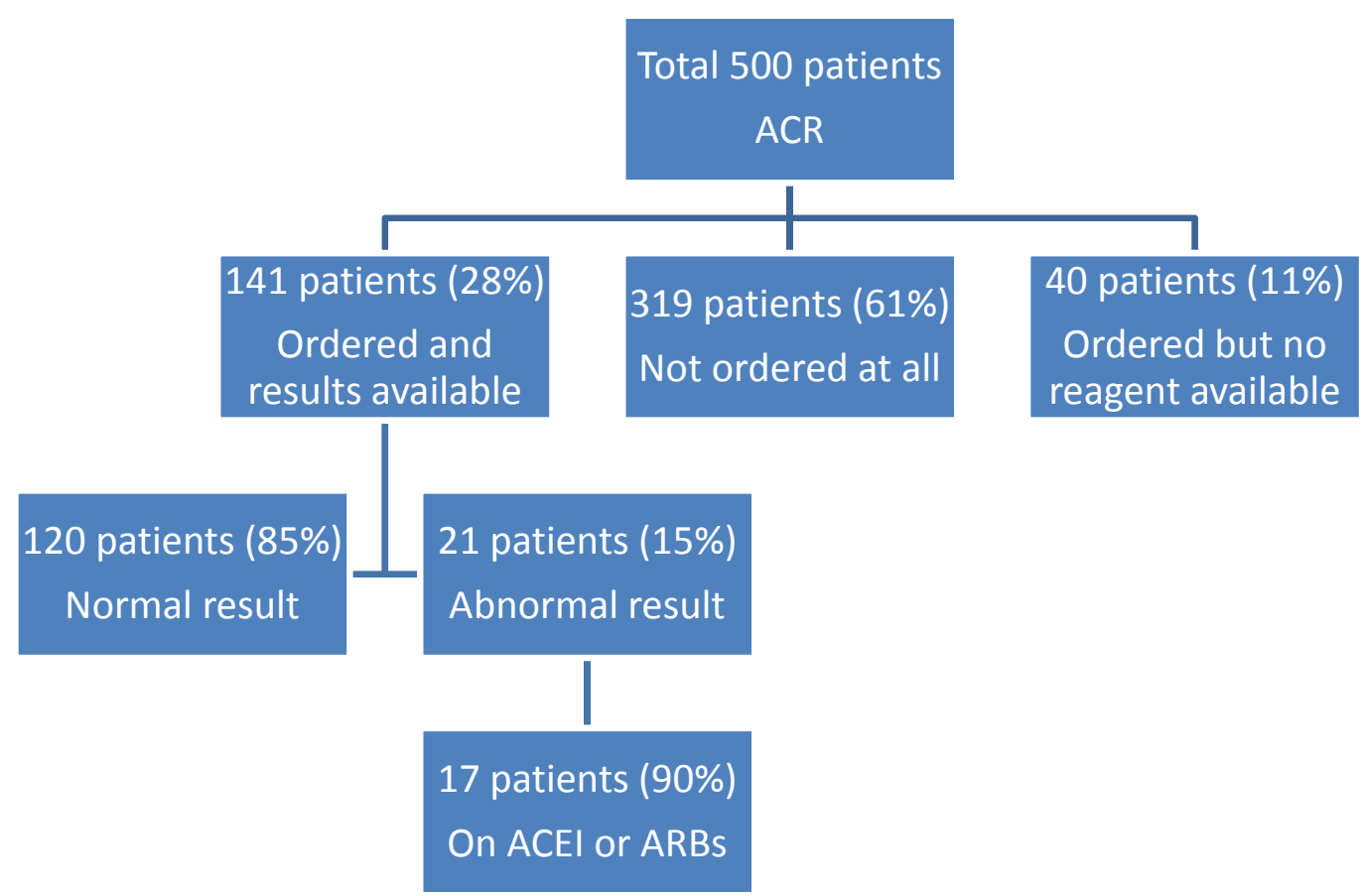

Fig. (4). Albumin creatinine ratio (ACR) results.

ACEI = Angiotensin converting enzyme inhibitor.

ARBs $=$ Angiotension receptor blockers.

Table 2. Description of ophthalmology review, foot examination and ECG documentation.

\begin{tabular}{|l|c|c|c|c|}
\hline \multicolumn{1}{|c|}{ Health Center } & Total & ECG & Foot Exam & Ophthalmology \\
\hline \hline Shinas & 95 & $1(1 \%)$ & 0 & $22(23 \%)$ \\
\hline Liwa & 15 & $1(7 \%)$ & $1(7 \%)$ & $1(7 \%)$ \\
\hline Sohar & 40 & $31(78 \%)$ & $191(98 \%)$ & $21(53 \%)$ \\
\hline Saham & 195 & $9(5 \%)$ & $3(2 \%)$ & $32(25 \%)$ \\
\hline Al-Khaburah & 130 & $53(41 \%)$ & 0 & $7(28 \%)$ \\
\hline Al-Suwaiq & 25 & $2(8 \%)$ & $197(39 \%)$ & $223(45 \%)$ \\
\hline \multicolumn{1}{c|}{ Total } & 500 & $97(19 \%)$ & & \\
\hline
\end{tabular}

ECG=Electrocardiogram

Percents are row percentages

With regards to aggressive lowering of $\mathrm{BP}$, caution should be exercised. As newer and more efficient drugs have been developed, it is possible to reduce the BP to very low levels. However, recent studies have shown that aggressive BP control might not be in the best interest of the patient. Low levels of diastolic BP have been associated with more cardiovascular events (a J-curve effect). In their study, Murphy et al, observed a J-curve effect for cardiovascular complications, for diastolic BP $<80 \mathrm{mmHg}$ and systolic BP $<130 \mathrm{mmHg}$ in a sub-analysis of the PROVE IT-TIMI 22 trial [28]. There was a trend in rounding up the BP reading to nearest 10th like $80,90,100$. The trap in such rounding ups is to acknowledge the consequences of small measurement inaccuracies. Errors of 5 to $10 \mathrm{mmHg}$ commonly occur as a result of improper BP technique [29]. Hence, health care professionals should be trained to record BP correctly.

One of the disturbing trends observed in the study was the poor availability of reagents, which in turn made unavailable the test results of some of the key tests associated with the management of DM, for example, HbA1c, lipid profile, creatinine and ACR Figs. (1-4). These deficits need to be addressed through proper health policies. In fact, availability of proper strategies improves management of DM. In a study by Nyomba et al., it was observed that availability of glucometer reagents increases the frequency of self-blood glucose monitoring and improves glycaemic control in patients with DM [30]. 
Health care professionals are key players in the optimal management of DM. However, our study shows that in many cases, specific tests that are key for DM management were not ordered. It is therefore, imperative that all health centre physicians involved in the management of DM be familiar with multiple laboratory tests that are used to diagnose and manage patients with DM. Our study shows that key tests like determination of $\mathrm{HbA}_{1 \mathrm{c}}$ (Fig. 1), was not ordered in 39\% of the patients. In fact, strict guidelines should be adhered to in the management of DM. Further, guidelines should undergo periodic updates. For example, for the management of DM in the United States draft guidelines were posted on the Internet and presented at the 2007 Arnold O. Beckman Conference. The document was tailored in response to oral and written comments, and a revised draft was posted in 2010 and again modified in response to written comments [31].The National Academy of Clinical Biochemistry and the Evidence-Based Laboratory Medicine Committee of the American Association for Clinical Chemistry jointly reviewed the guidelines, which were accepted after revisions by the Professional Practice Committee and subsequently approved by the Executive Committee of the American Diabetes Association [31]. Attending health-care professionals at health centres should be familiar with the updated guidelines. In order to facilitate this process clinical workshop(s) should be conducted from time to time by a central organization.

Our study show that at present there is a lack of adequate DM care in the north Al-Batinah governorate of Oman. This is primarily attributed to a lack of implementation of the existing guidelines to manage this debilitating condition. However, suitable measures should be provided by the authorities to address the problem with urgency. In addressing the sustainability of an effective DM program, patient and clinician barriers should be considered, which in turn would reduce the considerable burden of DM on Omani society.

\section{CONFLICT OF INTEREST}

The authors declare no conflict of interest with respect to the authorship and/or publication of this article.

\section{FUNDING}

The authors received no financial support for the research, authorship and/or publication of this article.

\section{ACKNOWLEDGEMENTS}

Declared none.

\section{REFERENCES}

[1] Al-Lawati JA, Barakat N, Al-Zakwani I, Elsayed MK, Al-Maskari M, Al-Lawati M. Control of risk factors for cardiovascular disease among adults with previously diagnosed type 2 diabetes mellitus: a descriptive study from a middle eastern Arab population. Open Cardiovasc Med J 2012; 6: 133-40.

[2] Al-Lawati JA, Mabry R, Mohammed AJ. Addressing the threat of chronic diseases in Oman. Prev Chronic Dis 2008; 5(3): A99.
Ramachandran A, Chamukuttan S, Shetty SA, Arun N, Susairaj P. Obesity in Asia--is it different from rest of the world? Diabetes Metab Res Rev 2012; 28(Suppl 2): 47-51.

Elliott JA, Abdulhadi NN, Al-Maniri AA, Al-Shafaee MA, Wahlstrom R. Diabetes self-management and education of people living with diabetes: a survey in primary health care in Muscat Oman. PLoS One 2013; 8(2): e57400.

Fowkes FG, Rudan D, Rudan I, Aboyans V, Denenberg JO, McDermott MM. Comparison of global estimates of prevalence and risk factors for peripheral artery disease in 2000 and 2010: a systematic review and analysis. Lancet 2013; 382(9901): 1329-40. Al-Shookri A, Khor GL, Chan YM, Loke SC, Al-Maskari M. Type 2 diabetes in the sultanate of Oman. Malays J Nutr 2011; 17(1): $129-41$.

Forbes JM, Cooper ME. Mechanisms of diabetic complications. Physiol Rev 2013; 93(1): 137-88.

Esposito K, Maiorino MI, Ceriello A, Giugliano D. Prevention and control of type 2 diabetes by Mediterranean diet: a systematic review. Diabetes Res Clin Pract 2010; 89(2): 97-102.

Handlos LN, Witte DR, Almdal TP, Nielsen LB, Badawi SE, Sheikh AR. Risk scores for diabetes and impaired glycaemia in the Middle East and North Africa. Diabet Med 2013; 30(4): 443-51.

Asfour MG, Lambourne A, Soliman A, Al-Behlani S, Al-Asfoor D, Bold A. High prevalence of diabetes mellitus and impaired glucose tolerance in the Sultanate of Oman: results of the 1991 national survey. Diabet Med 1995; 12(12): 1122-5.

Al-Lawati JA, Mohammed AJ. Diabetes in Oman: comparison of 1997 American Diabetes Association classification of diabetes mellitus with 1985 WHO classification. Ann Saudi Med 2000; 20(1): 12-5.

Al-Lawati JA, Al Riyami AM, Mohammed AJ, Jousilahti P. Increasing prevalence of diabetes mellitus in Oman. Diabet Med 2002; 19(11): 954-7.

Parati G, Bilo G, Ochoa JE. Benefits of tight blood pressure control in diabetic patients with hypertension: importance of early and sustained implementation of effective treatment strategies. Diabetes Care 2011; 34 (Suppl 2): S297-S303.

Cooper-DeHoff RM, Gong Y, Handberg EM, Bavry AA, Denardo SJ, Bakris GL. Tight blood pressure control and cardiovascular outcomes among hypertensive patients with diabetes and coronary artery disease. JAMA 2010; 304(1): 61-8.

Julius S, Majahalme S, Palatini P. Antihypertensive treatment of patients with diabetes and hypertension. Am J Hypertens 2001; 14(11 Pt 2): 310S-6S.

Frayne SM, Halanych JH, Miller DR, Wang F, Lin H, Pogach L. Disparities in diabetes care: impact of mental illness. Arch Intern Med 2005; 165(22): 2631-8.

Halanych JH, Wang F, Miller DR, Pogach LM, Lin H, Berlowitz DR. Racial/ethnic differences in diabetes care for older veterans: accounting for dual health system use changes conclusions. Med Care 2006; 44(5): 439-45.

Egede LE, Mueller M, Echols CL, Gebregziabher M. Longitudinal differences in glycemic control by race/ethnicity among veterans with type 2 diabetes. Med Care 2010; 48(6): 527-33.

Standards of medical care in diabetes. Diabetes Care 2004; 27 (Suppl 1): S15-S35.

Banerjee Y, Taranikanti V, Bayoumi R. Triglyceride-mediated pathways and coronary heart disease. Lancet 2010; 376(9745): 956-8.

Al-Mandhari A, Al-Zakwani I, El-Shafie O, Al-Shafaee M, Woodhouse N. Quality of diabetes care: A cross-sectional observational study in Oman. Sultan Qaboos Univ Med J 2009; 9(1): 32-6.

Alhyas L, McKay A, Balasanthiran A, Majeed A. Quality of type 2 diabetes management in the states of the Co-operation Council for the Arab States of the Gulf: a systematic review. PLoS One 2011; 6(8): e22186.

Grant RW, Buse JB, Meigs JB. Quality of diabetes care in U.S. academic medical centers: low rates of medical regimen change. Diabetes Care 2005; 28(2): 337-442.

Tricco AC, Ivers NM, Grimshaw JM, Moher D, Turner L, Galipeau J. Effectiveness of quality improvement strategies on the 
management of diabetes: a systematic review and meta-analysis. Lancet 2012; 379(9833): 2252-61.

[25] Fleg JL, Mete M, Howard BV, Umans JG, Roman MJ, Ratner RE. Effect of statins alone versus statins plus ezetimibe on carotid atherosclerosis in type 2 diabetes: the SANDS (Stop Atherosclerosis in Native Diabetics Study) trial. J Am Coll Cardiol 2008; 52(25): 2198-205.

[26] Weinreich M, Frishman WH. Antihyperlipidemic therapies targeting PCSK9. Cardiol Rev 2014; 22(3): 140-6.

[27] Stein EA, Gipe D, Bergeron J, Gaudet D, Weiss R, Dufour R. Effect of a monoclonal antibody to PCSK9, REGN727/SAR236553 , to reduce low-density lipoprotein cholesterol in patients with heterozygous familial hypercholesterolaemia on stable statin dose with or without ezetimibe therapy: a phase 2 randomised controlled trial. Lancet 2012; 380(9836): 29-36.

[28] Murphy SA, Cannon CP, Wiviott SD, McCabe CH, Braunwald E. Reduction in recurrent cardiovascular events with intensive lipid- lowering statin therapy compared with moderate lipid-lowering statin therapy after acute coronary syndromes from the PROVE ITTIMI 22 (Pravastatin or Atorvastatin Evaluation and Infection Therapy-Thrombolysis In Myocardial Infarction 22) trial. J Am Coll Cardiol 2009; 54(25): 2358-62.

[29] Handler J. The importance of accurate blood pressure measurement. Perm J 2009; 13(3): 51-4.

[30] Nyomba BL, Berard L, Murphy LJ. Facilitating access to glucometer reagents increases blood glucose self-monitoring frequency and improves glycaemic control: a prospective study in insulin-treated diabetic patients. Diabete Med 2004; 21(2): 129-35.

[31] Sacks DB, Arnold M, Bakris GL, Bruns DE, Horvath AR, Kirkman MS. Guidelines and recommendations for laboratory analysis in the diagnosis and management of diabetes mellitus. Diabetes Care 2011; 34(6): e61-e99.

Received: March 04, 2014

Revised: May 06, 2014

Accepted: May 06, 2014

(C) Al-Shafaee et al.; Licensee Bentham Open.

This is an open access article licensed under the terms of the Creative Commons Attribution Non-Commercial License (http://creativecommons.org/licenses/ by-nc/3.0/) which permits unrestricted, non-commercial use, distribution and reproduction in any medium, provided the work is properly cited. 